\title{
ПАРОДИЙНОЕ В АВТОРСКОЙ ПЕСНЕ
}

\author{
PARODY IN AN AUTHOR'S SONG
}

\author{
БАРТОШ ОСЕВИЧ
}

\begin{abstract}
In this article parody is analyzed as a type of intertextuality. A reader can only understand an artistic text which is a parody when he/she notices the contrast between its subject matter and form. Parody appears in Aleksandr Galich's and Vladimir Vysotsky's author's songs on different structural levels. Both poets purposefully chose the material to initiate a parodic game. The former prefers to interact with an elitist listener who comprehends the multi-level textuality of his works, while the latter refers to well-known literary texts.
\end{abstract}

Bartosz Osiewicz, Uniwersytet im. Adama Mickiewicz w Poznaniu, Poznań - Polska.

Поиски пародийного начала в авторской песне перспективно начать исходя из концепции интертекстуальности, которая была разработана в конце 60-х годов прошедшего столетия французскими семиологами, вдохновленными бахтинскими идеями „чужого слова” и „диалогичности" 1 , с целью показать способность художественного текста вступать в диалог с другими текстами и открыть новые перспективы изучения его смысловой стороны. Поэтому необходимо вспомнить ставшие каноническими формулировки, которые понятиям „интертекст" и „интертекстуальность” дали их создатели - Юлия Кристева, которая утверждает, что „любой текст строится как мозаика цитаций, любой текст есть продукт впитывания и трансформации какого-нибудь другого текста" 2 , и ее учитель Ролан Барт, который констатирует, что „каждый текст является интертекстом; другие тексты присутствуют в нем на различных уровнях в более или менее узнаваемых формах: тексты предшествующей культуры и тексты окружающей культуры"з.

1 См.: М. Б а х т и н, Проблемы поэтики Достоевского, Москва 1972; W. R a p a k, Bachtinowskie korzenie intertekstualności, [в:] Intertekstualność i wyobraźniowość, pod red. B. Sosień, Kraków 2003, c. 35-59.

2 Цит. по: В.Е. Х а л и з е в, Теория литературы, Москва 2002, с. 293. См. также: J. K r i s t e v a, Słowo, dialog i powieść, przeł. W. Grajewski, [в:] M. Bachtin. Dialog, język, literatura, pod red. E. Czaplejewicza i E. Kasperskiego, Warszawa 1983, c. 394-418.

${ }^{3}$ Р. Б а р т, Избранные работы: семиотика. Поэтика, пер. с фр./сост., общ. ред. и вступ. ст. Г.К. Косикова, Москва 1989, с. 418. Цит. по: http://yanko.lib.ru/books/ cultur/bart-all.htm (21.12.2005). 
Одновременно следует пояснить, что в свете семиотики как текст, который является носителем информации и который можно прочитать, стало рассматриваться все: литература, культура, общество, история, сам человек. Это положение, как утверждает крупный русский философ и культуролог Илья Ильин, „привело к восприятию человеческой культуры как единого интертекста, который, в свою очередь, служит как бы предтекстом любого вновь появляющегося текста"4.

На почве этих суждений актуальны выводы американского литературоведа Джонатана Каллера, который совершенно справедливо замечает, что „произведения порождаются другими произведениями, впитывая более ранние тексты, повторяя их, оспаривая, трансформируя"5. В связи с положением, что смысл возникает благодаря межтекстовому диалогу, интересны наблюдения французского литературоведа Жерара Женетта, который в своей работе под заглавием Палимпсесты: митература во второй степени выделяет пять типов взаимодействия текстов, среди которых четвертый тип, называемый гипертекстуальностью, появляется тогда, когда новообразованный текст (именуемый гипертекстом) соединяется с текстом уже существующим (именуемым гипотекстом) и пародирует или осмеивает его ${ }^{6}$.

Интертекстуальный характер пародии, представляющей собой, по Михаилу Гаспарову, комическое подражание отдельному художественному произведению или целой группе произведений ${ }^{7}$, бесспорен и вполне очевиден, ибо она немыслима вне присутствия других текстов, несмотря на вид знаков, которые являются их составляющими (отсюда использование пародии в музыке, изобразительном искусстве или кинематографе). В этой связи следует также учесть слова Валентина Хализева, утверждающего, что „пародия в состоянии существовать лишь за счет «непародийной» литературы, питаясь ее соками"8. Поэтому, в свете высказываний ученого, пародийные произведения, от природы направленные на другие тексты, являются своеобразной реакцией на них, а их настоящий смысл зависит от правильного опознания паро-

4 И.П. И л ь и н, Интертекстуальность, [в:] Литературная энизиклопедия терминов и понятий, гл. ред. и сост. А.Н. Николюкин, Москва 2003, с. 307.

5 Д. К а л л е р, Теория литературы: краткое въедение, пер. с англ. А. Георгиева, Москва 2006, с. 40.

${ }_{6}^{6}$ См.: M. G ł o w i ń s k i, O intertekstualności, [в:] его же, Poetyka i okolice, Warszawa 1992, с. 94-95; Н.С. О л и з ь к о, Интертекстуальность постмодернистского художественного дискурса (на материале творчества Дж. Барта). Попытка семиотико-синергетического анализа, Челябинск 2007, с. 46.

${ }^{7}$ М.Л. Г а с п а р о в, Пародия, [в:] Литературная энициклопедия..., указ. соч., c. $721-722$.

8 В.Е. Х а л и з е в, указ. соч., с. 284. 
дируемых текстов. В случае, когда идентификация текста-донора не заканчивается благополучно, смысл нового текста, который тогда не воспринимается как текст-пародия, является неполноценным. Конечно, поверхностное чтение новообразованного текста может вызывать у реципиента реакции, схожие с теми, которые возникают в процессе сознательного восприятия пародии, поскольку по аналогии с ней карикатура или отражение лица в кривом зеркале смешны сами по себе, однако они увеличиваются благодаря точному определению, „чье лицо" изображается или отражается, какой текст вышучивается или осмеивается.

Пародийное начало, характерное для многих видов искусства, свойственно и авторской песне, представляющей собой уникальное поэтическое явление, возникшее в период „оттепели" как альтернатива официальной литературе и отличающееся синкретизмом слова, музыки и исполнения. Оно проявляется не только на уровне стихотворного текста, но и расширяется на остальные компоненты жанра, которые как увеличивают впечатление от стихов, так и являются источником новых смыслов. Поэтому его обнаружение часто требует от реципиента целостного восприятия песенного произведения, которое не ограничивается традиционной моделью чтения напечатанного текста, а заключается в постижении „эффекта комплексности”, который создается в момент исполнения песни поэтом-певцом (неслучайно авторская песня в большей мере предназначается „для звучания", чем „для печати"). Благодаря фонограммам и сохранившимся отдельным видеозаписям из выступлений поэтов-бардов слушатели могут понять добавочные смыслы, вытекающие из синтеза всех составляющих жанра авторской песни. Особого внимания заслуживает использование поющими поэтами телесного кода, элементами которого, по Юлии Башкатовой, являются жесты, поза, выражение лица, кивки головы, движение и контакт глаз 9 . С его помощью легче уловить пародийность многих произведений, в которых поэтический текст контрастирует с рядом сопровождающих его невербальных компонентов, где патетика соседствует с насмешкой. К этому следует еще добавить музыкальный элемент и исполнение, поскольку гитарный аккомпанемент, тембр голоca, интонация, использованная мелодия могут быть источником пародийного в „магнитофонной лирике” бардов, если они противоречат содержанию текста. На роль „интонационной” и „мелодической” пародии обращал уже внимание Юрий Тынянов, который в своей, ставшей классической, статье $O$ пародии писал: „Попробуем прочесть ка-

${ }_{9}^{9}$ См.: Ю.А. Б а ш к а т о в а, Интертекстуальность словесно-художественного портрета: учебное пособие, Кемерово 2006, с. 26. 
кое-либо стихотворение с интонациями, взятыми из другого речевого ряда, с интонациями, например, делового сдержанного разговора - и получится пародия. То же и с напевом"10. Таким образом, то, что теоретически осмыслялось литературоведом, на практике реализовалось поэтами-бардами, которые свои или позаимствованные мелодии, а также определенную интонацию использовали в пародийных целях.

Подводя некоторые итоги, следует подчеркнуть, что понимание художественного текста как текста-пародии происходит лишь в случае, когда реципиент осознает его универсальную способность вступать в диалог с другими текстами (в том числе с текстами других видов искусства: музыки, живописи, киноискусства - что особо важно в случае синкретического жанра авторской песни) и сосредоточивает внимание на наличии в нем внешних связей, которые формируют его смысл, основанный, в первую очередь, на резком несоответствии тематического и стилистического планов, на контрасте между предметом и формой изображения. Их обнаружение и прочтение согласно авторской интенции свидетельствует о высокой степени подготовленности читателя, который в поисках смысла стремится к сопоставлению текстов, а не базируется лишь только на анализе внутритекстовых элементов, изолированных от окружающего их интертекстуального пространства, в пределах которого в результате взаимодействия разного рода текстов возникают многоуровневые связи между ними.

Пародийное в авторской песне ярче всего проявляется в творчестве двух классиков жанра, развивающих его эпико-повествовательную ветвь, - Владимира Высоцкого и Александра Галича. Уже первые поэтические опыты младшего художника слова связаны с искусством пародии. Пишет об этом в своем исследовании Владислав Зайцев, указывая на роль данного типа творчества в сложном процессе поиска формы писателем, который на рубеже 50-х и 60-х годов прошлого столетия начал „подбирать аккорды” к собственным текстам ${ }^{11}$. Доказательством ориентации молодого поэта-барда на произведения других авторов являются также слова Владимира Новикова, утверждающего, что в поэзии Высоцкого „все начинается с пародирования, шутливого копирования чужих стилей и языков"12. Ученый обращает внимание на пародийное начало поэтического творчества актера-певца в своих более ранних трудах, где акцентировал его аналитичное отношение к сочинитель-

10 Ю.Н. Т ы н я н о в, О пародии, [в:] его же, Поэтика. История литературы. Кино, Москва 1977, с. 301. Цит. по: http://feb-web.ru/feb/classics/critics/tynianov/t77/t77284-.htm (26.06.2012).

${ }_{11}$ См.: В.А. 3 а й ц е в, В.С. Высоцикий, [в:] его же, Русская поэзия ХХ века: 19401990-е годы, Москва 2001, с. 169.

12 В.И. Н о в и к о в, Высоикий, Москва 2003, с. 31. 
ству в пределах жанра пародии ${ }^{13}$. Центральное место пародии в раннем творчестве Высоцкого подчеркивается и Ниной Рудник, заметившей, что „пародия помогла обрести опору в литературной традиции и, отталкиваясь от нее, найти свою неповторимую интонацию, свое решение пародируемой темы" 14 .

Замечания и соображения критики по отношению к наличию пародийного в авторских песнях Высоцкого актуально и в контексте песенного творчества Галича, которое соединяет в себе мнимую простоту и настоящую литературность. „Истоки высокой русской культуры лежат глубоко в низах, в стихии пародийности и комизма"15 - пишет Марина Князева, увидевшая в Галиче поэта, который прекрасно понимал эту закономерность и оставался верным этой традиции. Ученая, называя его „мастером контрастов и контрапунктов”, выявляет суть эстетики писателя, которая основана на „несовместимости, разрыве, взрывоопасном столкновении грубопросторечного жизненного факта и изысканной, филигранной художественности его отделки"16. Так, игра контрастами является одним из более распространенных художественных приемов Галича, что отмечалось и Николаем Богомоловым ${ }^{17}$. Словесные и сюжетные контрасты, контрасты между формой и содержанием многих произведений Галича являются доказательством редкого пародийного таланта, которым обладал автор Песни исхода.

Согласно концепции Тынянова пародия может быть направлена на какое-либо произведение или определенный ряд произведений, „причем их объединяющим признаком может быть - жанр, автор, даже то или иное литературное направление"18. Галич и Высоцкий, работая со словом, тщательно выбирали художественный материал для пародийного обыгрывания в своих песнях-стихотворениях. Так, младший бард, при жизни претендуя на всенародное признание, объектом пародии в подавляющем большинстве случаев делает те тексты литературы, которые хорошо известны любому его слушателю. В отличие от Высоцкого, его старший коллега по перу и гитаре предпочитает „сотрудничество” с изысканным, элитным, подготовленным читателем, который поймет суть его интертекстуальных произведений.

13 В.И. Н о в и к о в, Владимир Высоцкий, [в:] его же, Авторская песня, Москва 2002, c. $69-70$.

14 Н.М. Ру д н и к, Проблема трагического в поэзии В.С. Высоияого, Курск 1995, с. 146.

${ }^{15}$ М. К н я $з$ е в а, Человек, назвавший себя городом, [в:] А.А. Г а л и ч, Возвращзается вечером ветер, Москва 2003, с. 209.

16 Там же, с. 210.

17 См.: Н.А. Б о г о м о л о в, Вольнолюбивая гитара, [в:] Поющие поэты, сост. и прим. Л.В. Поликовской, предисл. Н.А. Богомолова, Москва 2008, с. 12.

18 Ю.Н. Т ы н я н о в, О пародии, указ. соч., с. 289. 
Пародийный потенциал Высоцкого-поэта, который в литературном каноне ищет материал для художественной обработки, выявляется в песнях, представляющих собой эффект творческого диалога автора Охоты на волков с Пушкиным. Русский классик, являющийся любимым писателем актера-исполнителя, многократно им пародируется, что заставляет слушателей и читателей песен-стихотворений барда задуматься над причиной шуточного обыгрывания им известных пушкинских мотивов и сюжетов. Этот ряд вопросов не является новым для современного высоцковедения, которое объектом литературоведческого анализа сделало высоцкие пародии произведений Пушкина ${ }^{19}$. Указанные работы российских ученых, безусловно, составляют прочную методологическую базу для дальнейшего исследования межтекстового диалога Высоцкого с его выдающимся предшественником.

Так, в авторских песнях актера-певца наблюдается тенденция к шуточному переосмыслению отдельных произведений Пушкина. В качестве примера можно назвать написанную в бурлескной манере балладу Лукоморья больще нет, в которой художник слова „низким” языком трактует высокие образы прошлой литературы, снижает их пафос и, не дискредитируя текста-источника, играет с ним, что придает возникшему тексту новое семантическое наполнение. Ее заглавие является наглядной отсылкой к прологу поэмы Пушкина Руслан и Людмила: „У лукоморья дуб зеленый; // Златая цепь на дубе том”20. Однако помещенная в нем информация контрастирует с содержанием пушкинского двустишия. Возникший диссонанс усиливают первые строки поэтического текста-пародии Высоцкого, в которых нарушается гармония сказочного мира, обрисованного Пушкиным:

$$
\begin{aligned}
& \text { Лукоморья больше нет, } \\
& \text { От дубов простыл и след,- } \\
& \text { Дуб годится на паркет - } \\
& \quad \text { так ведь нет: } \\
& \text { Выходили из избы } \\
& \text { Здоровенные жлобы - }
\end{aligned}
$$

19 См.: С. С в и р и д о в, На фоне Пушкина..., Университет. Калининград: КГУ, 1994, 27 июня, http://vv.mediaplanet.ru/static/upload/SWIR1994.doc (19.06.2012); его же, Высоикий и Пушкин: по пути травестии, [в:] „Внимая звуку струн твоих...”. Сборник статей, сост. Ф.З. Кичатов, Калининград 1996, с. 14-19; А.В. К у л а г и н, „Лукоморья больше нет”. В жанре „антисказки”, [в:] его же, Высоикий и другие. Сборник статей, Москва 2002, с. 89-99.

20 А.С. П у ш к и н, Собрание сочинений в восьми томах, т. 4, Москва 1969, с. 34. Все дальнейшие цитаты, кроме особо оговоренных, приводятся по этому изданию с указанием в квадратных скобках: П, номера тома и страницы. 
Порубили все дубы

на гробы ${ }^{21}$.

Поступающий процесс утраты положительных качеств действительностью, созданной русским классиком, отражается на уровне интертекстуальных отношений между двумя текстами, которые перекликаются неоднократно 22 :

И днем и ночью кот ученыи Все ходит по цепи кругом; Идет направо - песнь заводит, Налево - сказку говорит. [П 4, 34]
Здесь и вправду ходит Kom, -

Как направо - так поет,

Как налево - так загнет

анекдот, -

Но, ученый сукин сын,

Цепь златую снес в торгсин на выручку - один в магазин. $[1,148]$

Возникшее у барда выразительное и яркое словесное изображение разрушенного пушкинского мира сказки, которое Анатолий Кулагин назвал „универсальной, «апокалиптичной» картиной всеобщего разорения" 23, следует соотнести с современной Высоцкому действительностью, в которой романтические идеалы не имеют права на существование. В этом заключается суть высоцкой пародии, целью которой не является осмеяние русского классика, но - как совершенно справедливо замечает Кулагин - попытка по образу древнерусской пародии запечатлеть переход „мира” в „антимир”, переосмыслить пушкинские мотивы в традициях смеховой культуры, чтобы лучше отразить ощущение кризиса мира накануне „застоя" 24 . К этому следует добавить цельное замечание Виктора Бахмача, который, сравнивая пушкинское Лукоморье, где царит русский дух, сказочная гармония и надежда на победу добра, с обреченным Лукоморьем Высоцкого, где нарушена гармония, акцентирует веру поэта-певца в силу свободного искусства, которое благодаря своей диалогичности способствовало „заострению социального видения у слушателя" 25.

Интересна также ориентация других песен-стихотворений Высоцкого на фольклорную традицию, к которой поэт обращается через

${ }^{21}$ В.С. В ы с о ц к и й, Сочинения В двух томах, т. 1, Екатеринбург 1997, с. 147. Все дальнейшие цитаты приводятся по этому изданию с указанием в скобках номера тома и страницы.

22 В приведенных ниже цитатах из пролога поэмы Пушкина Руслан и Людмила и песни Высоцкого Лукоморья больще нет курсив мой (Б. О.).

23 А.В. Ку л а г и н, Поэзия В.С. Высоикого. Творческая эволюиия, Москва 1997, с. 83.

24 А.В. К у л а г и н, „Лукоморья больше нет”..., указ. соч., с. 93, 99.

25 В.И. Б а х м а ч, Пушкинские мотивы в ранних перепевах Высоикого, „Русская филология" 1997, № 1-2, с. 46-47. 
произведения Пушкина, выполняющие функцию мостов, соединяющих два полюса русской культуры. Среди них можно упомянуть Сказку о несчастных сказочных персонажах и Песню о вещем Олеге. Первое стихотворение, где признаки современности: „На горе стояло здание ужасное, // Издаля напоминавшее $\mathrm{OOH}^{\prime \prime}[1,150]$ соединяются со сказочной действительностью, созданной Высоцким путем включения в собственный текст интертекстуальных элементов, роль которых выполняют в этом случае имена литературных персонажей (напр. Кощей Бессмертный, Добрый молодец Иван, бабы-яги), близко песне Лукоморья больще нет. Во втором наблюдаются многочисленные переклички с пушкинским текстом-донором - стихотворением под заглавием Песнь о вещем Олеге. Оба произведения начинаются почти одинаково:

Как ныне сбирается вещий Олег

Отмстить неразумным хозарам,

Их селы и нивы за буйный набег

Обрек он мечам и пожарам;

С дружиной своей, в цареградской броне, Князь по полю едет на верном коне ${ }^{26}$.
Как ныне сбирается вещий Олег Щита прибивать на ворота,

Как вдруг подбегает к нему человек И ну шепелявить чего-то.

„Эх, князь, - говорит ни с того ни с сего, Ведь примешь ты смерть от коня своего!"

И хотя в обоих рассказывается одна и та же история трагической гибели князя Олега, то они отличаются друг от друга существенным образом. В песне Высоцкого пародийной трактовке подвергается тема, первоначально разработанная Пушкиным. Нельзя не согласиться в этом отношении с Бахмачем, соотнесшим бурлескное и травестийное начала произведения поэта-исполнителя со стремлением художника к семантической игре со слушателем/читателем, который „через знакомые сюжеты, персонажи и фразы” предпримет попытку „осмыслить актуальные проблемы" 27. Противопоставление и переосмысление образов сказочного пушкинского мира и пропитанной советским духом художественной действительности Песни о вещем Олеге Высоцкого дает возможность уяснить масштаб созданных им строк, которые, не разрушая своей литературной основы, кодируют информацию о горькой участи истинной русской культуры.

Источники указанных песен-пародий Высоцкого, составляющих „пушкинский слой" его произведений, легко узнаются слушателями барда, которые - как и его песенные герои - принадлежат к различным слоям общества, являются представителями разных профессий. В этом заключается основная разница между художественной стратегией поющего актера Таганки и автора Матросской тищины, который

26 А.С. П у ш к и н, Собрание сочинений в восьми томах, т. 2, Москва 1967, с. 155.

27 В.И. Б а х м а ч, указ. соч., с. 45. 
материал для пародирования находит в самых разнообразных пластах русской и мировой культуры. Пародийные отсылки в песнях Галича проявляются на нескольких уровнях их структуры. Среди текстовых элементов в первую очередь следует назвать заглавие, которое всегда содержит в себе определенную информацию насчет следующего за ним основного текста, образует контекст для его прочтения, благодаря чему выполняет существенную функцию в процессе интерпретации произведения. В авторских песнях Галича заглавие часто является интертекстуальной отсылкой к другим текстам. Такого рода прием использовал поэт в песне Смерть Ивана Ильчча, название которой является пародийным повторением заглавия одноименной повести Льва Толстого. Совпадение заглавных компонентов произведений барда с художественными текстами других авторов представляет собой неслучайный, глубоко осознанный творческий метод, вызванный желанием интертекстуальной игры с читателем. Галич часто добивался задуманного семантического эффекта, ссылаясь на чужие произведения, перенося значение со структуры собственного текста в пространство межтекстовых связей. Это явление наблюдается и в песне Левый марш, которая расширяет генологический репертуар поэзии драматурга-певца новым „музыкальным” жанром. Галич, пользуясь искусством пародии, вызывает на литературную дуэль Владимира Маяковского, заимствуя заглавие одного из его стихотворений. Бард, продолжая стихотворный монолог о времени, произнесенный футуристом, чтобы вдохновить матросов, защищающих революцию („Крепи // у мира на горле // пролетариата пальцы! //Грудью вперед бравой! //Флагами небо оклеивай! // Кто там шагает правой? // Левой! //Левой! // Левой!"28), не разделяет энтузиазма своего предшественника насчет победы Октября, по жизненному опыту зная ее горькие последствия („Сколько раз нам ломали ребра, // Этот - помер, а тот - ослеп, //Но дороже, чем ребра - вобла // И соленый мякинный хлеб. // Левой, левой, левой, //Левою, шагом марш!" 29).

Рядом с верным копированием уже существующих названий литературных произведений в поэтическом наследии Галича встречаются и пародийные цитатные заглавия. Ярким примером применения этой стратегии является песня Счастье было так возможно, ассоциирующаяся с поэмой Пушкина Евгений Онегин. У барда объект пародии представляет собой помещенный в заглавии отрывок из речи Татьяны,

28 В.В. М а я к о в с к и й, Должник Вселенной, состав., вступ. ст. А.М. Ушаков, Москва 2000, с. 74-75.

29 А. Г а л и ч, Стихотворения и поэмы, вступ. статья, сост., подг. текста и примеч. В. Бетаки, Санкт-Петербург 2006, с. 89. Все дальнейшие цитаты приводятся по этому изданию с указанием в квадратных скобках номера страницы. 
произнесенной ей во время последней встречи с Онегиным: „«А счастье было так возможно, // Так близко!.. Но судьба моя // Уж решена. Неосторожно, // Быть может, поступила я: // [...]// Я вас люблю (к чему лукавить?), // Но я другому отдана; //я буду век ему верна»"30. Новый пародийный смысл, который слова русского классика XIX века получают в современном литературном контексте, сигнализируется Галичем в предваряющем песню авторском комментарии ${ }^{31}$. Он развивается на сюжетном уровне произведения (в центре изображения находится чекист, который выражает сожаление, что не составит дуэта со своей жертвой, поскольку слишком поздно узнал о ее вокальных возможностях), которое резко отличается от своего пушкинского источника. Исследуя указанную авторскую песню Галича как текст-пародию, особо важно обратить внимание на синкретичный характер жанра, в рамках которого она возникла. Так, поэтический текст, который является ее доминантой, сопровождается другими существенными составными элементами, такими как мелодия, исполнение, интонация, жест и мимика. Несмотря на то что при сопоставлении со стихотворным текстом перечисленные компоненты играют лишь служебную роль, зачастую они могут выполнять функцию генератора новых смыслов, которые недоступны в случае анализа зафиксированных в печатном виде произведений Галича, а также других поэтов-бардов. Таким образом, интертекстуальный характер песни-пародии Счастье было так возможно проявляется и на музыкальном уровне, поскольку автор исполняет ее на мелодию французской Марсельезы.

Среди компонентов, окружающих основной текст произведений Галича, существенную роль играют эпиграфы. Их значение, как по отношению к жанру авторской песни, так и гитарной поэзии Галича, отмечалось уже литературоведением ${ }^{32}$. Рядом с цитатами из художествен-

30 А.С. П у ш к и н, Евгений Онегин, [в:] его же, Стихотворения. Поэмы. „Евгений Онегин”. Драматические произведения. Проза, вступ. ст. Д.С. Лихачева, Москва 2008, c. $456-457$.

31 Галич говорил:

Песня, она возникла так. У меня год тому назад, то ли под влиянием, так сказать, каких-то событий в жизни моих друзей или даже не друзей, всяких людей, я стал бояться, что меня собьет машина. Не случайно, а умышленно. Для того чтобы перестать бояться этого я решил сочинить коротенькую антипесню. Называется она Счастье было так возможно.

Цит. по фонограмме: А. Галич, Песня исхода.

32 См.: Е.А. А б р о с и м о в а, Специфика эпиграфра В бардовской песне, [в:] Художественный текст и языковая личность. Материалы IV Всероссийской научной конференции (27-28 октября 2005 г.), под ред. проф. Н.С. Болотновой, Томск 2005, с. 229-234; А.Е. К р ы л о в, Галич - „Соавтор”, Москва 2001, с. 38-114; А.В. К у л а г и н, Эпиграфр в поэзии Галича, [в:] Галич. Новые статьи и материалы, сост. А.Е. Крылов, Москва 2003, c. $155-162$. 
ных текстов самых выдающихся представителей русской культуры, которые предпосланы отдельным произведениям Галича, следует назвать пародийные эпиграфы, предваряющие его шуточные песни. Наиболее ярким примером высмеивания в пределах основного текста цитаты, выступающей в качестве эпиграфа, является сказовая Баллада о прибавочной стоимости, в которой пародируется знаменитая строка из Манифреста Коммунистической партии Маркса и Энгельса. Их лозунг „Призрак бродит по Европе, призрак коммунизма...", неточно процитированный Галичем [193], при столкновении с текстом его издевательской песни ${ }^{33}$ теряет свою силу и превращается в объект насмешки. Таким образом, в балладе поэта-барда одновременно реализуются две функции комизма пародии, выделенные Галиной Лушниковой, - критиковать и веселить ${ }^{34}$.

В творчестве обоих поэтов-певцов, рядом с пародиями на конкретные произведения отдельных авторов, можно встретить примеры жанровой пародии. Наиболее показательными в этом плане являются Горестная ода счастиивому человеку Галича и Пародия на плохой детектив Высоцкого. Ода, как жанр лирической поэзии, в рамках авторской песни модифицируется поэтом-драматургом, который в художественных целях отбрасывает ее отдельные черты, оставаясь верным лишь части критериев, которые ставит перед ней генология. Автор посвящает ее незаурядной личности - Петру Григорьевичу Григоренко, который, бросив генеральские эполеты и лояльность коммунистической власти, выбрал активность в диссидентском движении и борьбу за гражданские права, за что был наказан типичным для времени „застоя” образом - заключен в психиатрическую больницу, а затем выслан за границу. Галич лишает оду некоторых канонических жанровых примет, редуцируя пафос и заменяя высокий стиль низким: „Он водку пил и пил одеколон, // Он песни пел и женщин брал нахрапом! // А сколько он повкалывал кайлом! // А сколько он протопал по этапам!" [167]. Этот прием частично проявляется уже на заглавном уровне, который своим звучанием противоречит торжественности и патетике жанра (слово „горестный” обозначает “проникнутый горем; печальный, скорбный', а также 'вызывающий чувство горечи, сожаления', 'жалкий,

33 В ней повествуется о герое, который „изучал «Капитал» с «Анти-Дюрингом»” и „наряжался на праздники призраком” [193], однако, несмотря на это, стал первой жертвой „штучек марксовых”, поскольку так и не смог получить в наследство имение в несуществующей стране Фингалии из-за совершившейся в ней революции и наступившей за ней национализации.

34 См.: Г.И. Л у ш н и к о в а, Интертекстуальность художественного произведения, Кемерово 1995, с. 71. 
плачевный'35). Совмещением в заглавии противоположных чувств подчеркивается идейный смысл стихотворения, в котором изображен презираемый властью человек, который несмотря на жестокую судьбу сохранил внутреннее счастье, источником которого была верность самому себе.

Интересный исследовательский материал представляет собой Пародия на плохой детектив Высоцкого, которая на первый взгляд является примером „двойной” жанровой пародии. Появляющееся в заглавии песни определение „плохой”, свидетельствующее о невысоком художественном уровне произведения, которое само по себе может восприниматься как пародия на лучшие достижения в области детективного романа 36 , усиливается введением в заглавный компонент названия жанра, являющегося комическим подражанием другим литературным формам. Однако этот необыкновенный словесной синтез на самом деле скрывает в себе второе дно, столь характерное для поэтики актера-певца. Объектом пародии является скрытый Высоцким в формулировке „плохой детектив" особый тип шпионского детектива советского времени, в котором, как отмечает литературоведение, „антагонистические противоречия сохраняются на уровне противоборства двух систем", а конфликт добра и зла рассматривается в идеологическом ключе ${ }^{37}$. Высоцкий в своей сказовой балладе вышучивает сюжетные схемы политических детективов, в которых победу всегда одерживает советский человек. Так, неслучайно его герой - гражданин Епифан, другим персонажем песни - иностранным агентом - воспринимаемый как стереотипный мужчина, который „меры в женщинах и в пиве не знал и не хотел", на самом деле является настоящим защитником своей родины - „чекистом, майором разведки и прекрасным семьянином", что, в свою очередь, вместо чувства гордости у слушателей Высоцкого вызывает смех, увековеченный на фонограммах из его выступлений.

Однако исполнитель авторских песен в пародийном слове не только высказывает мысль, продолженную позже литературоведением, обратившим внимание на „вялое” развитие русского детектива вплоть до середины XX века 38 , одновременно повторяя идею Тынянова, что „пародийные произведения обыкновенно бывают направлены на явления

35 Большой толковый словарь русского языка, под ред. С.А. Кузнецова, Санкт-Петербург 2000, с. 219.

36 О детективном романе см., напр.: R. C a i 11 o i s, Powieść kryminalna, [в:] его же, Siła powieści, przekład i posłowie T. Swoboda, Gdańsk 2008, c. 37-65.

37 См.: Д.Д. Н и к о л а е в, Детектив, [в:] Литературная энциклопедия..., указ. соч., с. 222-223.

38 См.: Основы литературоведения, под общ. ред. В.П. Мещерякова, Москва 2000, c. 52 . 
современной литературы" 39 , но и с его помощью выражает другие смыслы. Именно поэтому бард-поэт в пародийных целях играет штампами официальной пропаганды, высмеивая укрепленное в обыденном сознании тех времен суждение, что идеальный образ советской России сознательно искажается ее неприятелями:

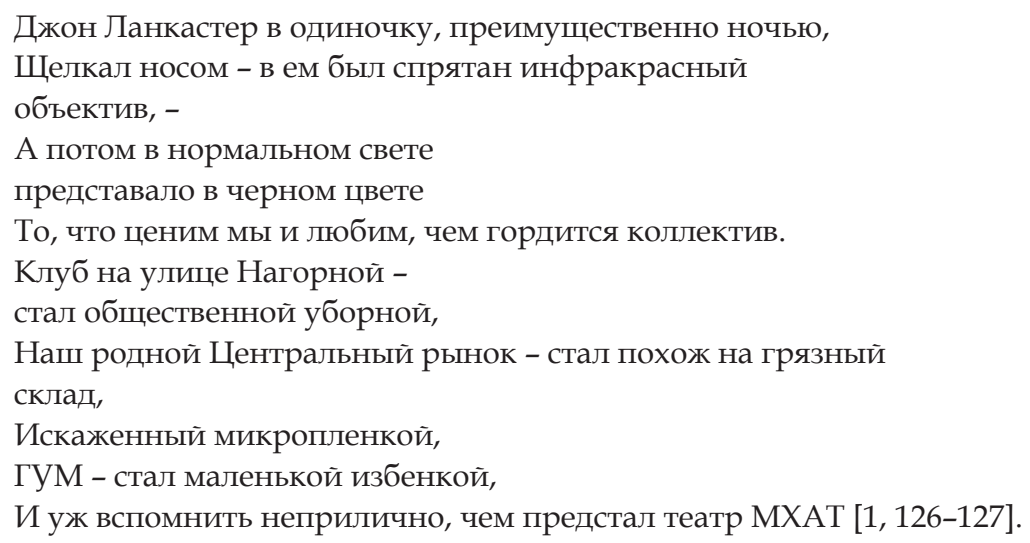

Следует отметить и подчеркнуть, что этот прием является весьма распространенным как в песенном творчестве Высоцкого, так и в авторских песнях Галича. Достаточно назвать знаменитую Инструкиию перед поездкой за рубеж, или Полчаса $b$ месткоме младшего барда или известный цикл Коломийцев b полный рост его старшего товарища, в которых объектом пародирования является сама действительность, которая изображается несерьезно, вызывая смех у слушателей. Это помогает понять исключительный пародийный дух художественного пространства их произведений, в которых в комическом ракурсе отражается современный поэтам мир.

Наконец следует подчеркнуть, что пародийные произведения обоих поэтов-бардов не всегда встречались с пониманием критики. В качестве примера можно назвать хотя бы разгромную статью Николая Мейсака, которая была яростной реакцией официальных кругов на выступление Галича на бардовском фестивале в Новосибирске в 1968 году ${ }^{40}$, или работу одного из современных исследователей авторской

39 Ю.Н. Т ы н я н о в, О пародии, указ. соч., с. 294.

40 Содержавшиеся в ней инвективы в адрес Галича переплетаются с идеологической оценкой его произведений. Именно поэтому процитированную в настоящей статье Балладу о прибавочной стоимости Мейсак называет попыткой „вдохновенно воспевать гнусненького типа, который готов продать за пятак свои убеждения". Н. М е й с а к, Песня - это оружие. Слушая запись выступлений „бардов", [в:] А. Г а л и ч, Избранные стихотворения, Москва 1989, с. 222 (репринт по: газета „Вечерний Новосибирск" 1968 год). 
песни - священника Михаила Ходанова ${ }^{41}$. Однако несмотря на подобного рода высказывания, пародия, как способ работы с „чужим словом”, является существенным элементом поэтической системы Высоцкого и Галича и активно проявляется на других уровнях жанра авторской песни, классиками которого стали оба писателя.

41 Ее автор утверждает, что Песня про плотника Иосифа, деву Марию, Святого Духа и непорочное зачатье, представляющая собой пародию на библейский текст, была „внушена Высоцкому космополитическим и враждебным Церкви окружением”. М. Х о д а н о в (священник), "Спасите наши души!..”. О христианском осмыслении поэзии В. Высоикого, И. Талькова, Б. Окуджавы и А. Галича, Москва 2000, с. 62. 